\title{
On the design strategy of Hongshan Cultural Museum Guided by the concept of local architecture
}

\author{
Lihua Zhang, \\ School of Resources,Environment and Architectural Engineering, Chifeng University, 024000, China
}

\begin{abstract}
This paper mainly analyzes the natural factors, historical and cultural factors and technical material factors of Hongshan cultural museum. Hongshan cultural museum inherits the urban context, coordinates the natural environment, and creates a typical museum building space environment with Hongshan cultural characteristics. The Hongshan Culture Museum makes Chifeng a city with recognizability, and shapes the Hongshan Culture in a three-dimensional and reasonable way.
\end{abstract}

\section{Introduction}

The trend of globalization has resulted in the convergence of regional culture, the loss of urban features in the process of urbanization, and the tendency of regional expression of architectural creation towards patternization, symbolization and visualization. However, this kind of phenomenon has a big deviation from people's individualized aesthetic orientation, open cultural image, emphasis on the influence of the social level, and no longer deliberately pursue a generally recognized way of thinking of cultural symbols. With the acceptance of critical architecture theory, there are various concept words in the architecture field, which reflect the architects' Thinking on the combination of architecture and local elements. Local architecture is one of them[1-2].

There has been a long discussion on the regional creation of architecture. In 1981, Alexander chunice and liana Lefebvre first proposed the concept of "critical regionalism" which is different from "traditional regionalism" in their article "network and path", advocating that architecture creation should pay attention to tradition and continue context. Mr. Wu Liangyong is an early architect who pays attention to Architectural Regionalism in China. In 1998, he put forward the idea of "modernization of local architecture and localization of modern architecture", which is an important theory in the study of regionalism in China. Moreover, in 2007, $\mathrm{Mr}$. Wu Liangyong also wrote a preface for the Chinese version of chunice's work Critical Regionalism Architecture and its characteristics in a globalized world. "The essence of critical regionalism is that it not only pays close attention to the cultural connotation of regional architecture, but also carries forward the spirit of criticism and creation of the times in a far-reaching way." [3-5].
Due to the domestic policy orientation, the actual opening time is relatively late. The architectural system missed the baptism of modern architectural theory, and then entered the post-modernism period of the desire for tradition, history, memory and cultural diversity. The gap in theory led to a kind of cultural tension. However, "critical regionalism" emphasizes symbols and context, which makes us skip the process of abstraction and accept the discussion of symbolic form more easily. Therefore, there are some misunderstandings in the early practice of "critical regionalism" in China. The regional expression of architectural creation ignores the historical conditions, geographical environment, social life, technical system and many other factors that produce regional architecture. It only flows into the traditional form of imitation and the reconstruction of cultural symbols, and tends to be patterned, symbolized and visualized. Nowadays, with the "critical regionalism" deeply rooted in people's minds, Chinese architects have been aware of and corrected the mistakes in the early regional practice, and have emerged a wealth of new regional architectural creation positions and viewpoints, such as local design, here and now, starting point and gravity, and the local architecture discussed in this paper. They all tend to have a common idea of local content.

Taking Hongshan Cultural Museum as an example, this paper studies the concept of local architecture, analyzes the relationship with critical regionalism, analyzes the innovative features of the concept of local architecture, sums up its response positions and ways in three dimensions of ecological nature, human history and construction technology, and then realizes that the concept of local architecture has an impact on local social life, traditional culture, environmental protection and culture, The emphasis on connotation and social responsibility.

\footnotetext{
* Corresponding author: zhanglihua3453@163.com
} 


\section{Overall planning}

The Hongshan Cultural Museum covers an area of 20335 square meters, with a total construction area of 8422.3 square meters, and a total investment of 68.43 million yuan is planned. The main works of the museum are divided into the first underground floor, the first overground floor and the second local floor, about 17.3 meters, as shown in Figure 1.

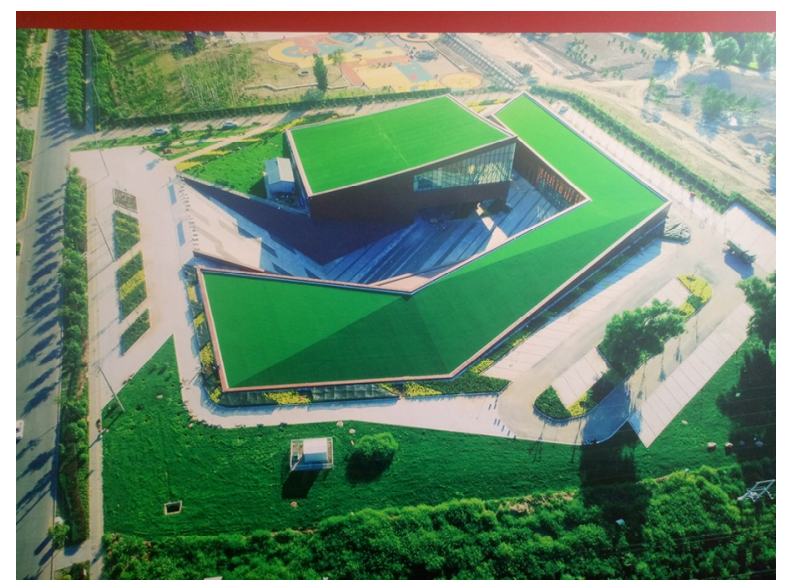

Figure 1. Overall structure of Hongshan Cultural Museum

The main exhibition area of Hongshan Cultural Museum consists of six parts: preface hall, dawn of civilization exhibition hall, Hongshan gem exhibition hall, Jingtian Fazu exhibition hall, diversified integrated exhibition hall and glorious history exhibition hall. It will dynamically interpret the ancient scenes of Hongshan culture period through the combination of real sand table and projection, diversified reading and other display methods. In addition to basic display, Hongshan cultural museum also has temporary exhibition hall, ring screen cinema, cultural and creative shop, academic lecture hall and other areas. It is a comprehensive museum integrating cultural relics collection, exhibition, protection, research, education and leisure functions. The layout is shown in Figure 2.

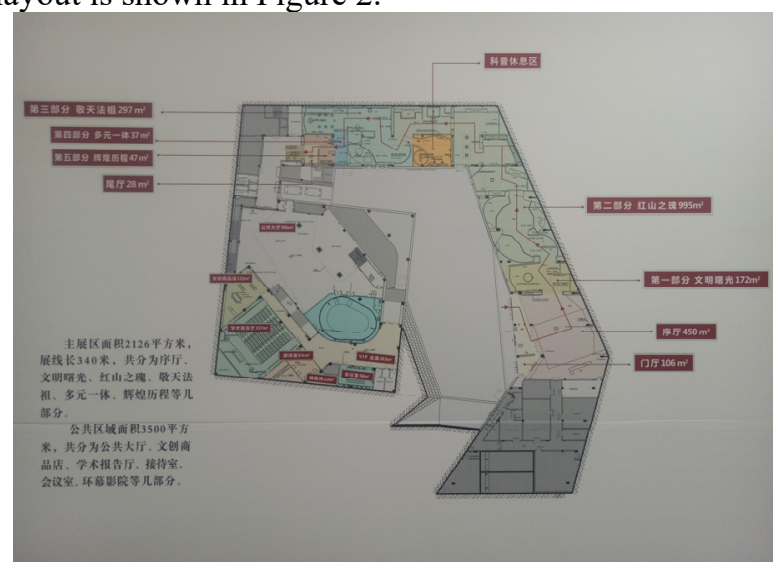

Figure 2. Exhibition layout map

\section{Analysis on the design strategy of Hongshan Cultural Museum}

In the types of public buildings, designers pay more attention to the regional cultural design of museums. A museum building that can integrate regional culture plays a key role in building city popularity and exporting city culture. In the design of museum buildings, the factors that affect the expression of regional culture in the space environment of museum buildings come from all aspects. In a comprehensive way, the external factors that affect museum buildings can be roughly divided into three categories: natural factors, cultural factors, and technical factors. To some extent, the interaction balance among these three external factors constitutes the source power of the evolution of regional culture in museum buildings.

\subsection{Utilization of natural factors}

Different natural environment produces different regional culture, and regional culture can be expressed in architecture, so the relationship between regional architecture and natural environment is inseparable. Buildings in different regions will show different characteristics, so will museum buildings. Architecture, as a product of human beings, is often inseparable from the natural environment in the process of human construction activities. In the relationship with the natural environment, it is ultimately a continuous adaptation. Therefore, for the regional characteristics of regional architecture, its characteristics are largely the result of the impact of natural environment factors [6-7] .

In the design of Hongshan Cultural Museum, the designer combined with the local climate conditions and adopted the method of centralized treatment in the form of architectural layout, using a huge concentrated body block and thick external wall to design. The museum opens large windows on the outer wall, and the designer designs the whole museum as a semi underground building, as shown in Figure 3. These methods are all for keeping warm and cold and reducing the building's figure coefficient.

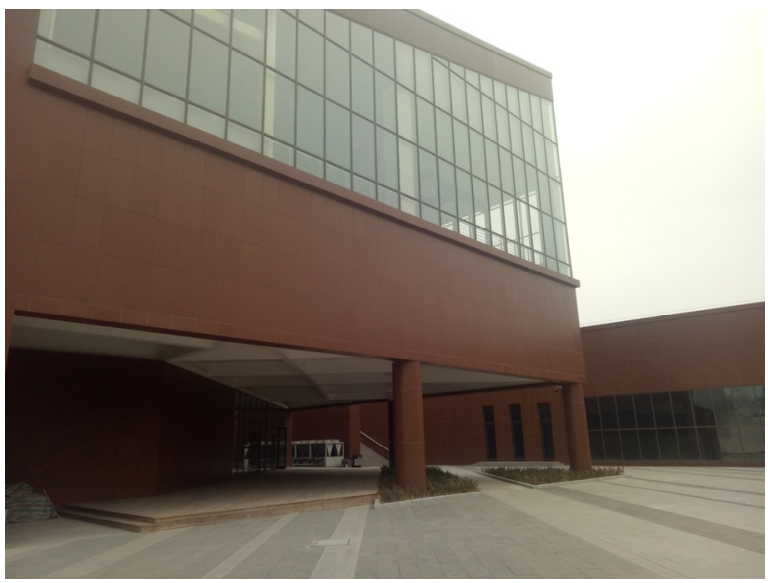

Figure 3. Thermal insulation building 
The overall layout of Hongshan cultural museum is combined with the topography, landform and geographical environment around the red line of the building. Considering the advantages and disadvantages of the surrounding environment, it can play its advantages, avoid its disadvantages, and coordinate the compatibility of the building and the environment as much as possible. The Hongshan cultural museum is located on the back of Hongshan mountain, echoing the highest peak of Hongshan mountain, highlighting the solid sense of heaviness and the sense of carving, such as stone moving, and the mountain feeling [8-10]. The skyline outline of the building corresponds to the skyline of the mountain, forming a complement and dialogue to the skyline of the mountain, as shown in Figure 4. The building integrates and renews the environment. From the perspective of architectural layout, this layout better conforms to the terrain, and also coordinates with the surrounding environment.

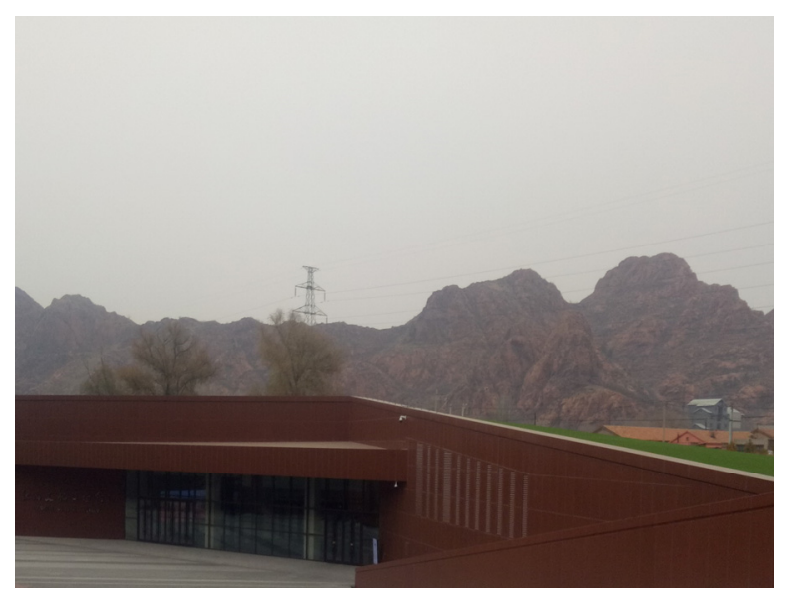

Figure 4. Adaptation map of the museum and the surrounding topography

\subsection{Historical and humanistic factors}

For the characteristics of regional architecture, it comes from the results of various factors. At present, the social attributes of human beings at the material and spiritual level are formed through long-term production activities, and these social attributes are reflected by the regional economic, life, customs, culture, history and other factors. In the design process of museum buildings, the influence of history and culture on the design process is not only the accumulation of elements, but also an extremely complex optimization design process. When we visit a city's Museum, we can always see the intricate connection between architecture and history and culture through its architectural form, exhibition contents, indoor and outdoor environment. Hongshan Culture Museum is also a museum that displays history and culture, so it pays more attention to historical and cultural factors [13].

Hongshan culture is centered on xilamuron River, Laoha River and Daling River, which are the tributaries of Liaohe River Basin, with a distribution area of 200000 square kilometers, about 56000 years ago and a lasting time of 2000 years. The social form of Hongshan culture was in the heyday of matriarchal society in the early stage, and the main social structure was the tribal group with the female blood group as the link. In the late stage, it gradually transited to the patriarchal clan. The main economic form is agriculture, and animal husbandry, fishing and hunting coexist. Its remains are of Neolithic culture, in which colorful pottery and zigzag pottery coexist with each other and have both fine stone tools. The residents of Hongshan culture are mainly engaged in agriculture, raising pigs, cattle, sheep and other livestock, and also engaged in fishing and hunting. In the stone tools, the two hole stone knives with the shape of tobacco leaf, grass foot and laurel leaf are characteristic agricultural tools, as well as the two hole stone knives made by grinding and punching. [11-12]

The exterior design of Hongshan Culture Museum is similar to that of the houses inhabited by the residents of Hongshan culture, as shown in Figure 5, and adopts the same sinking architectural style, which perfectly matches with Hongshan culture.

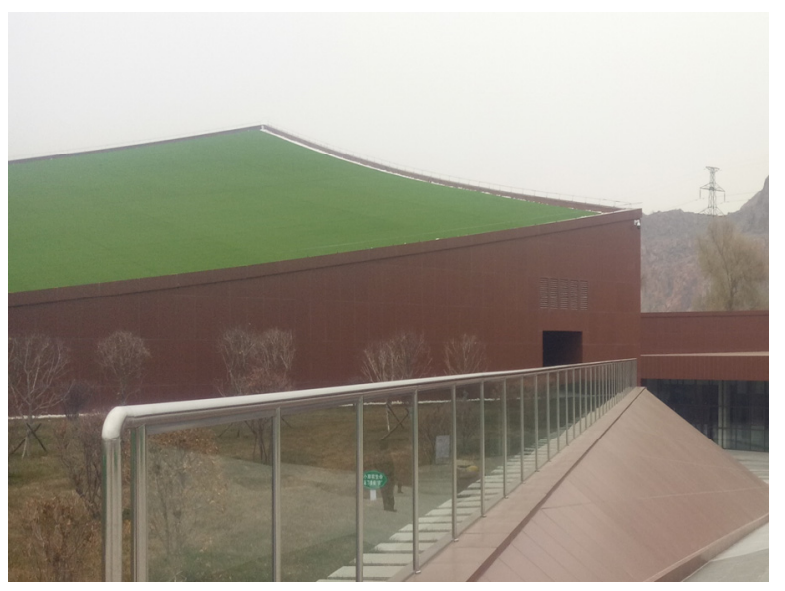

Figure 5. Shape of antique building

\subsection{Technical material factors}

With the development of the times, the traditional technology alone can not meet the needs of people, especially after the industrial revolution, the use of frame structure, steel structure, long-span structure and other structural forms makes the building break through the limitations of the original storey height and span, and has made breakthrough innovations in the internal space and external modeling, new materials such as reinforced concrete The texture, texture and color of steel, glass, etc. also greatly expand the expressiveness of contemporary architecture. However, when using modern technology, it is impossible to completely separate from the regional environment, or to respond to the local characteristics of nature and humanity or technology[14-15].

Although the Hongshan culture museum uses modern concrete materials, it fully considers the local natural address characteristics. In order to fully express the Hongshan Culture and break into the cultural symbol of Hongshan, the walls of the museum have been designed obliquely, with a well arranged and angular external 
form, and the building and the local environment are fully integrated. As shown in Figure 6.

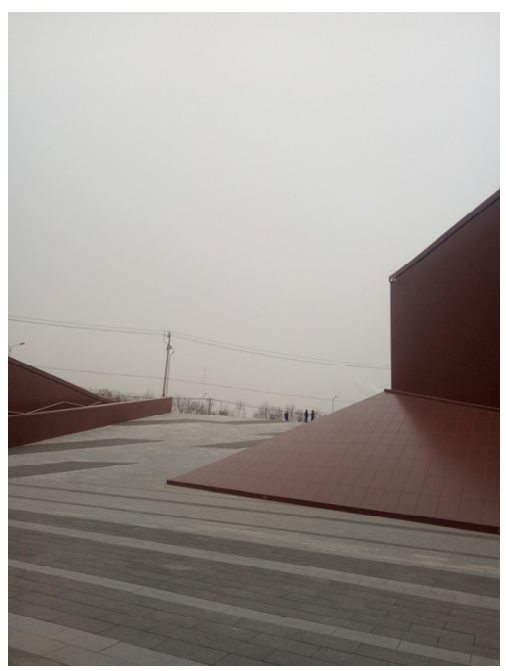

Figure 6. Sharp external shape

\section{Conclusion}

Hongshan Culture Museum perfectly interprets the regional culture in museum buildings. The whole building inherits the urban context, coordinates the natural environment, selects the regional materials, uses high-tech to carry out the overall design, and creates a typical museum building space environment with the characteristics of Hongshan culture. The Hongshan Culture Museum makes Chifeng a city with recognizability, and shapes the Hongshan Culture in a three-dimensional and reasonable way.

\section{References}

1. Ernest R. Alexander. Chance and Design:From Architecture to Institutional Design. Journal of the American Planning Association,2017,83(1):93-102

2. Ann Thorpe. Applying Protest Event Analysis to Architecture and Design . Social Movement Studies, 2014,13(2):275-295

3. Ralph Evins . A review of computational optimisation methods applied to sustainable building design . Renewable and Sustainable Energy Reviews,20 1 3,22:230-245

4. Catharina Nord . Design according to the law:juridical dimensions of architecture for assisted living in Sweden. Journal of Housing and the Built Environment, 2013,28(1):147-155

5. Andrew Sempere. Architecture and Design for Virtual Conferences:A Case Study. Future Intemet, 2011,3(3):175-184

6. Claude M. H. Demers,Andrd Potvin. Erosion in architecture:a tactile design process fostering biophilia . Architectural Science Review,
2017,60(4):325-342

7. F. Malekpoor Mansoorkhani G. B . Seymour, R . Swamp,H . Moeiniyan Bagheri,etc. Environmental,developmental,and genetic factors controlling root system architecture. Biotechnology and Genetic Engineering Reviews,2014,30(2):95112

8. Christopher Rodning - Place,Landscape, and Environment:Anthropological Archaeology in 2009. American Anthropologist,2010,112(2):180190

9. Abiodun Akeem Oladiti,Dorcas Oluwaseyi Adeoye,Ajibade Samuel Idowu. Maxwell Fry and Jane Drew Partners:The Contributions of British Architects to Built Environment in Colonial Nigeria,1 946-1 959 . Hist6ria-Revista da Faculdade de Letras da Universidade do Porto,2016,6(a6): : 269-288

10. Jeffrey D . Wilson . Rescaling to the IndoPacific:From Economic to Security - Driven Regionalism in Asia. East Asia, 2018,35(2):177-1 96

11. Joel Rathus. Indonesia and ASEAN Plus Thi'ee Financial Cooperation:Domestic Politics,Power Relations, and Regulatory Regionalism. Bulletin of Indonesian Economic Studies,2018, 54(1):131-133

12. Trudie Waiters . Facilitating well-being at the second home:the role of architectural design. Leisure Studies, 2017,36(4):493-504

13. Milena Medineckiene,Zenonas Turskis,Edmundas Kazimieras Zavadskas . Sustainable construction taking into account the building impact on the environment . Journal of Environmental Engineering and Landscape Management,2010,8(2):118-127

14. Richard Harris,Nadine Dostrovsky. The Suburban Culture of Building and the Reassuring Revival of Historicist Architecture Since 1970 . Home Cultures,2008,5(2):167-196 